\title{
(

\section{Effect of ethylene treatment on phytochemical and ethylene-related gene expression during ripening in strawberry fruit Fragaria x ananassa cv. Camino Real}

\author{
P.Z. Lopes ${ }^{1}$, I.M. Fornazzari', A.T. Almeida², C.W. Galvão ${ }^{3}$, R.M. Etto ${ }^{4}$, J. Inaba ${ }^{4}$ \\ and R.A. Ayub ${ }^{1}$ \\ ${ }^{1}$ Laboratório de Biotecnologia Vegetal, Departamento de Fitotecnia e Fitossanidade, \\ Universidade Estadual de Ponta Grossa, Ponta Grossa, PR, Brasil \\ ${ }^{2}$ Departamento de Bioquímica e Biologia Molecular, Universidade Federal do Paraná, \\ Curitiba, PR, Brasil \\ ${ }^{3}$ Laboratório de Biologia Molecular Microbiana, Departamento de Biologia Estrutural, \\ Molecular e Genética, Universidade Estadual de Ponta Grossa, \\ Ponta Grossa, PR, Brasil \\ ${ }^{4}$ Departamento de Química, Universidade Estadual de Ponta Grossa, \\ Ponta Grossa, PR, Brasil \\ Corresponding author: R.A. Ayub \\ E-mail: rayub@uepg.br \\ Genet. Mol. Res. 14 (4): 16113-16125 (2015) \\ Received April 30, 2015 \\ Accepted September 1, 2015 \\ Published December 7, 2015 \\ DOI http://dx.doi.org/10.4238/2015.December.7.23
}

ABSTRACT. In contrast to climacteric fruits, in which ethylene is known to be pivotal, the regulation of ripening in non-climacteric fruits is not well understood. The strawberry is a typical example of a non-climacteric fruit, which has been used as a model system of these types of fruit. In this study, the effect of exogenous ethephon on the expression of ethylene biosynthesis and signaling genes, FaERF2 and FaACO1, was analyzed in the Fragaria ananassa cultivar Camino Real by quantitative real-time polymerase chain reaction, and the physicochemical and phytochemical 
characteristics of fruits were evaluated in field trials and postharvest tests. Transcript accumulation was influenced by exogenous treatment with ethephon, which affected the pattern of gene expression during different stages of growth and fruit development, with the highest expression occurring during postharvest tests. In addition, ethephon significantly influenced the phytochemical profile of sugars, anthocyanins, phenolic compounds, and vitamin $\mathrm{C}$ contents both in the field- and postharvesttreated fruits at different stages. These results indicate that ethylene regulates the phenylpropanoid maturation pathway in strawberry fruit.

Key words: Strawberry; Non-climacteric fruit; Ethylene signaling; RT-qPCR; Ripening genes

\section{INTRODUCTION}

Strawberries are one of the most economically important fruits (Quesada et al., 2009) and their consumption has rapidly increased (Ji et al., 2012) mainly due to improvements in their flavor and nutritional quality (Symons et al., 2012). The strawberry is a non-climacteric fruit, which is a member of the Rosaceae family. It is the only representative of this family that shows fast herbaceous and perennial growth, a fast reproductive cycle, and easy propagation for genetic transformation. Furthermore, it harbors a small genome of $\sim 240 \mathrm{Mb}$ in size, which offers advantages for research, and is a good model for use in biotechnological studies (Shulaev et al., 2011).

Ethylene is primarily related to the ripening of climacteric fruits (Symons et al., 2012), but its importance in non-climacteric fruit should also be considered. Non-climacteric fruits are able to synthesize ethylene; therefore, the involvement of this hormone in physiological and molecular events has been reported during strawberry development and ripening (Trainotti et al., 2005; Villarreal et al., 2010; Merchante et al., 2013; Sun et al., 2013).

The introduction of exogenous ethylene in fruits of the strawberry cultivars Toyonoka and Camarosa during their white stage increased anthocyanin, sugar content, and polygalacturonase activity (Villarreal et al., 2010; Sun et al., 2013), while treatment with 1-methylcyclopropene (1MCP), a cyclic ethylene analog, had the opposite effect (Villarreal et al., 2010).

Some genes related to ethylene signaling and biosynthesis are present both in climacteric and non-climacteric fruits. ETR and ERS encode the first subfamily of ethylene receptor proteins (ETR), which are located in the membrane of endoplasmic reticulum (Shakeel et al., 2013). ERF encodes an ethylene response transcription factor, which is located in the nucleus, and ACC oxidase, coded by ACO, is a cytosolic enzyme that converts 1-aminocyclopropane-1-carboxylic acid (ACC) to yield ethylene and $\mathrm{CO}_{2}$ (Trainotti et al., 2005; Bombarely et al., 2010; Zhao and Guo, 2011).

In the Fragaria $\mathrm{x}$ ananassa Duch (Fa) cultivar Chandler, FaETR1 and FaETR2 were found to be more responsive to exogenous ethylene treatment during the early stages of fruit development (white fruits). On the other hand, FaERS1 was found to have the highest response in red fruits (Trainotti et al., 2005). This indicates that either the ethylene receptors differ from those found in climacteric fruits or that they have different functions in non-climacteric fruits (Tian et al., 2000). A significant increase in the FaACO1 transcript was also detected after treatment of fruits with ethylene (Trainotti et al., 2005). Phytochemical and molecular analyses showed that different cultivars respond differently to the application of exogenous plant growth regulators. In addition, 
available data so far exclude the existence of a unique regulatory model for all fruits, or of a single growth regulator, that has a positive role in non-climacteric ripening fruit (Trainotti et al., 2005).

Strawberry perishability is problematic during production, harvesting, and storage. Therefore, knowledge about fruit ripening might lead to better postharvest handling and an increase in fruit production (Symons et al., 2012). To investigate the role of ethylene in fruit of the Fragaria $\mathrm{x}$ ananassa Duch. cultivar Camino Real at different stages of development, target gene expression and physicochemical and phytochemical characteristics were evaluated.

\section{MATERIAL AND METHODS}

\section{Plant material}

Strawberry plants (Fragaria x ananassa Duch. cultivar Camino Real) were grown from May to December 2012, outdoors at a commercial property under plastic cover, in Ponta Grossa city, PR state, latitude $24^{\circ} 59.082^{\prime} \mathrm{S}$, longitude $50^{\circ} 15.903^{\prime} \mathrm{W}$ and altitude $912 \mathrm{~m}$ (GPS BAK/Model BK-GPS 7008 DTBC). Fruits were treated and analyzed during four developmental stages: green ( 7 days after anthesis - DAA), white (17 days DAA), pink (21 days DAA), and red (24 days DAA).

\section{Ethylene treatment}

The fruits were injected with water or ethephon $(100 \mu \mathrm{L} 2 \mathrm{mM}$ 2-chloroethylphosphonic acid, Ethrel 720 Bayer diluted in $2 \%$ ethanol solution), which were applied directly into the receptacle of the fruits attached to the plant (field test) or after harvest (postharvest test) and then maintained under laboratory conditions of $20 \pm 2{ }^{\circ} \mathrm{C}$. Molecular analyses was performed at 0,4 , and $24 \mathrm{~h}$ posttreatment. The whole fruits (receptacles plus achenes) were collected and frozen in liquid nitrogen and stored at $-80^{\circ} \mathrm{C}$ prior to total RNA extraction. Physicochemical analyses were performed 0,24 , and $48 \mathrm{~h}$ after treatment. The fruit pulps were frozen in $\mathrm{a}-30^{\circ} \mathrm{C}$ freezer until analysis.

\section{Molecular analysis}

\section{RNA isolation and cDNA synthesis}

For total RNA extraction, $100 \mathrm{mg}$ of crushed strawberry whole fruits (three fruits in triplicate) were treated with Plant RNA Reagent $\left(\right.$ Ambion $^{\circledR}$ ) and $2 \mu \mathrm{L}$ Turbo DNA Free ${ }^{\text {TM }}$ (Ambion, Life Technologies, CA, USA), according to the manufacturer protocol. RNA integrity and purity were analyzed by electrophoresis on $1.0 \%(\mathrm{w} / \mathrm{v})$ agarose gel, and at $A_{260} / A_{280}$ rate, respectively. cDNA was obtained using RevertAid H Minus First Strand cDNA Synthesis kit (Thermo Scientific, USA), with $1 \mu \mathrm{g}$ RNA and oligodT, following the manufacturer protocol.

\section{Relative quantitative real-time polymerase chain reaction (RT-qPCR) analysis}

RT-qPCR was performed on a LightCycler ${ }^{\circledR}$ Nano platform (Roche Diagnostics $\mathrm{GmbH}$, Mannheim, Germany), using $2 \mu \mathrm{L}$ cDNA in a system containing $1 \mu \mathrm{L}$ forward and reverse primer $(10 \mu \mathrm{M}), 10 \mu \mathrm{L}$ FastStart Essential DNA Green Master 2X (Roche), in a final volume of $20 \mu \mathrm{L}$. The following program was used: pre-incubation for $10 \mathrm{~min}$ at $95^{\circ} \mathrm{C}$, followed by 45 cycles of $20 \mathrm{~s}$ at $95^{\circ} \mathrm{C}, 20 \mathrm{~s}$ at $60^{\circ} \mathrm{C}$, and $20 \mathrm{~s}$ at $72^{\circ} \mathrm{C}$. 
Gene-specific primer sequences were as follows: FaERF2 (Bombarely et al., 2010), FaACO1 (forward: 5'-TGCTTTTGTTGCGAAATCAG-3'; reverse: 5'-ACCAAGTCCACTTCCAC CAG-3'). Primers specific for actin (Chai et al., 2011; Sun et al., 2013) and the intergenic region 26S-18S (Cumplido-Laso et al., 2012) were used as internal standards. Data obtained were analyzed using the qPCR instrument software version 1.0 (LightCycler Nano System, 2011).

\section{Physico- and phytochemical analysis}

Physicochemical analyses were performed using nine fruits and phytochemical analyses where made with a sample containing 30 fruits, and were performed in triplicate. The following physicochemical features of fresh pulps were evaluated: 1) firmness, using an Instrutherm DD200 penetrometer (8-mm tip diameter, expressed in Newton, N); 2) epidermis surface color (expressed as Hue angle, $\mathrm{H}^{\circ}$ ), using a Minolta CR 310 colorimeter (Mcguire, 1992); 3) soluble solids (SS ${ }^{\circ} \mathrm{Brix}$ ) (AOAC, 2002); and 4) titratable acidity (expressed as TA \% citric acid) (AOAC, 2002). The following phytochemical parameters of thawed fruit pulps were analyzed: 1) phenolic compounds (expressed as $\mathrm{mg}$ of gallic acid/100 $\mathrm{g}$ fresh pulp weight) according to the Folin-Ciocalteau method, using a calibration curve with gallic acid as the standard (Singleton and Rossi, 1965); 2) anthocyanins (expressed as mg cianidin-3-glycoside/100 $\mathrm{g}$ fresh pulp weight), by the differential $\mathrm{pH}$ method at 520-700 nm in a spectrophotometer (Shimadzu) (Giusti and Wrolstad, 2003); 3) vitamin C (expressed as mg ascorbic acid/100 g pulp), using the Tillmans method (AOAC, 2002); and 4) total sugars $(\mathrm{g} / 100 \mathrm{~g})$, by the phenol-sulfuric method, using a calibration curve with glucose as the standard (Dubois et al., 1956).

\section{Experimental design and statistical analysis}

Physiological analyses were conducted independently. For each analysis, three technical repetitions were performed. The experimental design was completely randomized with 24 treatments arranged in a $2 \times 4 \times 3$ factorial design (treated and untreated fruits; stages of development; time after treatment application). The physiological results were submitted to analysis of variance (ANOVA), and the significance of the comparison between means was assessed by the Tukey test at $\mathrm{P} \leq 0.05$, using the statistical computer program $S A S^{\circledR}$ 9.1.3. The results of relative quantification analysis of gene transcripts (FaERF2, and FaACO1) were obtained using the software version 1.0 of the qPCR instrument (LightCycler ${ }^{\circledR}$ Nano System, 2011).

\section{RESULTS}

The effect of exogenous ethylene treatment on strawberry fruits at different stages of development was monitored by RT-qPCR analysis of FaERF2 and FaACO1 expression and by physiological analyses.

\section{Effect of exogenous ethylene on FaERF2 and FaACO1 expression in strawberries}

Ethephon treatment promoted accumulation of the FaERF2 transcript in fruit during green, white, and pink stages after 4 and $24 \mathrm{~h}$ of treatment. There was an increase ( 50 -fold) in FaERF2 gene expression in ethephon-treated fruit within $24 \mathrm{~h}$ compared to that observed at $0 \mathrm{~h}$ and in the control, both in white and pink fruits (Figure 1A). Conversely, ethephon had only a minimal effect 
on FaERF2 expression in the green and red stages.

There was a 100-fold increase in FaACO1 expression in white fruits after $24 \mathrm{~h}$ of treatment (Figure 1B). The same level of FaACO1 gene expression was observed across all fruit development stages, except for the white stage, in which expression increased independently of ethylene treatment (Figure 1B). In general, the highest level of this transcript was observed in ethylenetreated fruits after $24 \mathrm{~h}$ of treatment. All selected genes were more highly expressed during the white stage and were decreased in the subsequent ripening stages.
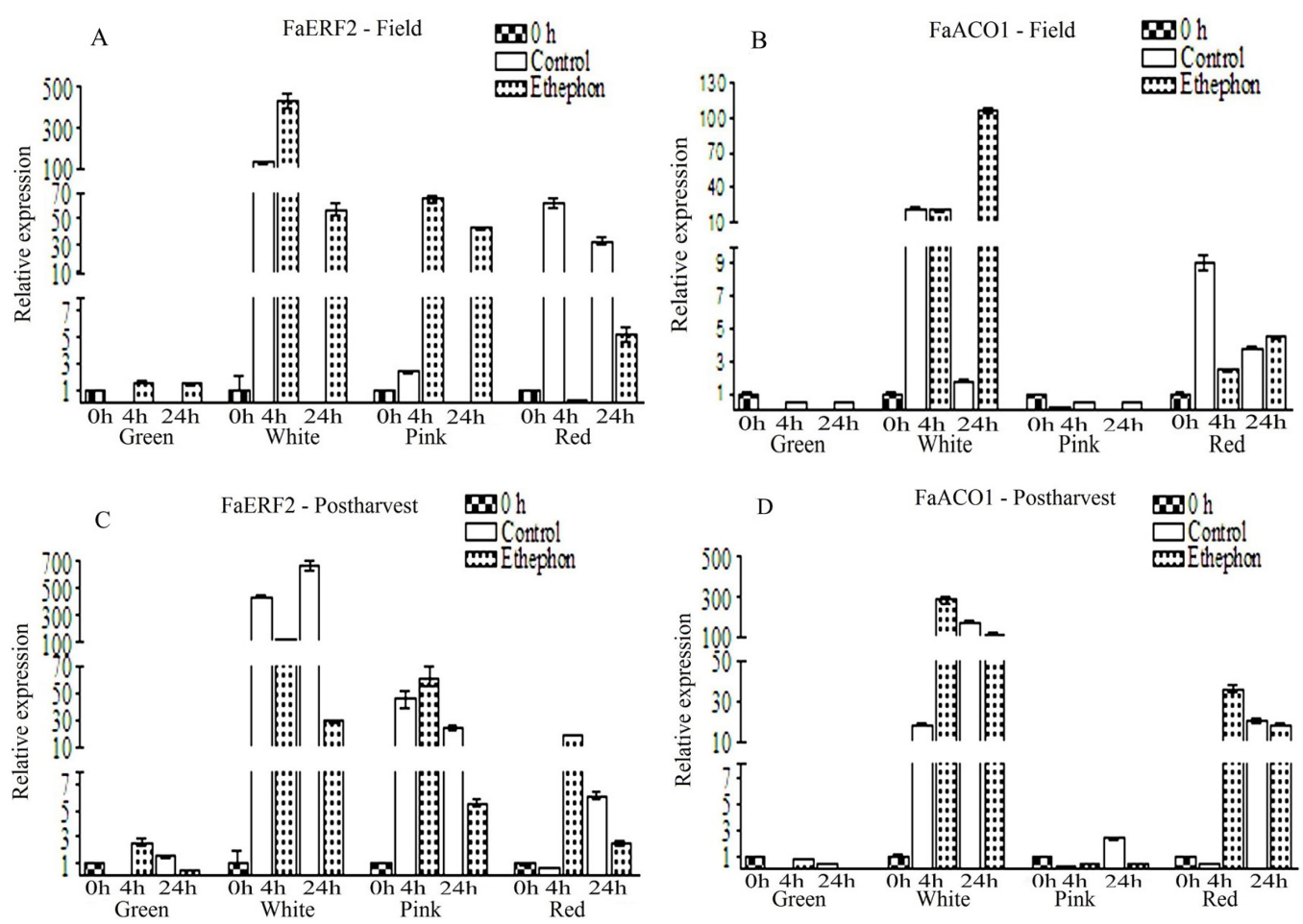

Figure 1. Relative expression profiles of FaERF2 and FaACO1 ethylene signaling and biosynthesis pathway genes from strawberry in green, white, pink, and red stages of development. RNA were extracted and analyzed by RT-qPCR in the control (open bars) and ethephon-treated (dotted bars) fruits after 0, 4 and $24 \mathrm{~h}$ of treatment, on the field (A and B) and postharvest ( $\mathbf{C}$ and $\mathbf{D})$. Time $(0 \mathrm{~h})$ represents fruits frozen at the beginning of the experiment. Values have been normalized to time $0 \mathrm{~h}$, arbitrarily set to 1 (checkered bars). Error bars represent the standard errors of the maximum and minimum of normalized expression.

\section{Effect of postharvest application of ethylene on FaERF2 and FaACO1 gene expression}

When fruits were harvested and treated with ethephon (postharvest treatment), a profile similar to that described above was observed.

FaERF2 was highly expressed in white control fruits, and reduced significantly as the fruit ripened (Figure 1C). Ethephon appeared to have little effect on FaERF2 expression during the early stages of development, but it effect decreases during ripening. 
Expression of FaACO1 in detached treated fruits was similar to that observed in fruits that remained on the vine; increased expression was found in the white stage, which decreased in the pink stage and subsequently increased in the red stage (Figure 1D). Ethephon was found to have a significant effect when the white and red fruits were analyzed after $4 \mathrm{~h}$ of treatment. Increased transcript levels were observed in both the white (15 fold) and red stages (91.8 fold) at $4 \mathrm{~h}$ compared to those in the control.

\section{Effect of exogenous ethylene on physiological characteristics of strawberry fruits}

\section{Field assay}

As fruits ripeed, the skin color intensified as the Hue angle $\left(\mathrm{H}^{\circ}\right)$ decreased (Figure 2A). At $0 \mathrm{~h}$, the $\mathrm{H}^{\circ}$ value decreased from106.95 \pm 0.64 in green fruit to $28.10 \pm 3.54$ in the red stage control fruit. Green-ethephon-treated fruits showed a reduced $\mathrm{H}^{\circ}$ within $48 \mathrm{~h}$ compared to that observed in the control fruits (Figure 2A). No significant interaction was found between ethephon treatment and fruit firmness (data not shown). Ethephon promoted an increase in the soluble solids levels (SS) in white fruit within $48 \mathrm{~h}$ of treatment $\left(6.43 \pm 0.06^{\circ} \mathrm{Brix}\right)$ compared to that observed in the control $\left(4.83 \pm 0.94^{\circ} \mathrm{Brix}\right)$ and in red fruit within $24 \mathrm{~h}\left(7.73 \pm 0.21^{\circ} \mathrm{Brix}\right)$ compared to control $(6.57 \pm 0.11$ ${ }^{\circ}$ Brix) (Figure 3A). Titratable acidity (TA) was affected by ethephon injection, as a lower value was found at some stages, mainly in white fruits (Figure $3 C$ ).
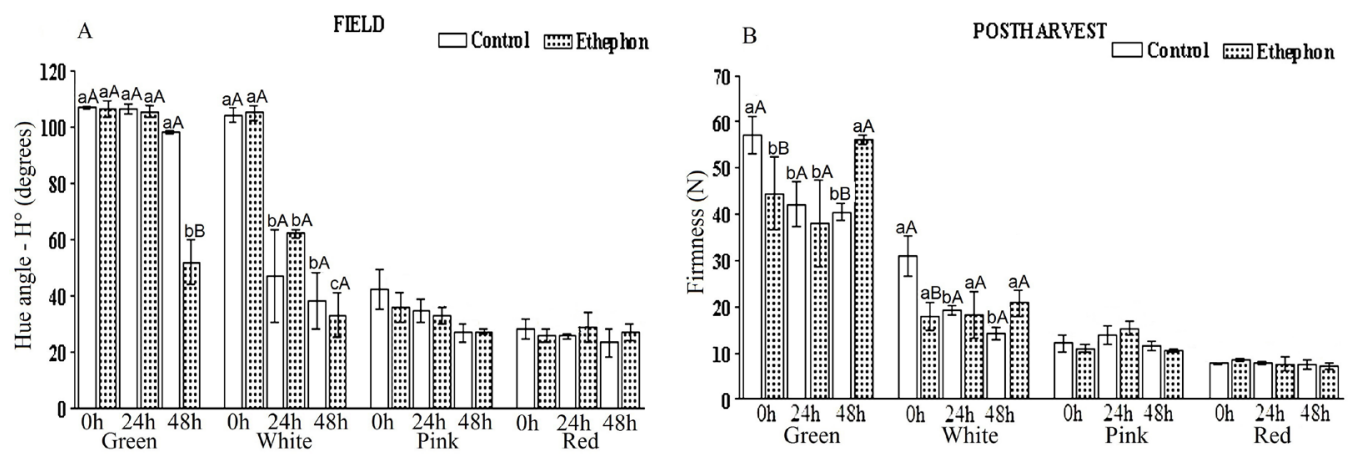

Figure 2. Changes of fruit color $\left(\mathrm{H}^{\circ}\right)(\mathbf{A})$ and firmness (B) in the green, white, pink, and red control (open bars) and ethephon-treated (dotted bars) field and postharvest fruits in times 0,24 and $48 \mathrm{~h}$. The error bars represent a standard deviation of three technical repetitions. Means followed by the same lowercase letters between the time intervals of evaluation within each stage in fruits with and without treatment and averages followed by the same uppercase letters between stages in fruits with and without treatment within each time interval did not differ significantly by the Tukey test at $P \leq 0.05$.

The role of ethylene in sugar accumulation became evident from the onset of fruit ripening, and a higher total sugar content was observed in the white ethephon-treated fruits compared to the controls over time (Figure 4A). Even though no difference was observed between treated and control pink fruit, there was an accumulation of sugar in the samples over time (Figure 4A). Anthocyanins were not found in green fruits (data not shown), but they were found to accumulate during ripening (Figure 4C). Regardless of ethephon application, there was a steady increase in the accumulation 
of anthocyanin during the different stages; reaching medianvalues of total anthocyanin content of $76.13 \mathrm{mg} / 100 \mathrm{~g}$ and $92.82 \mathrm{mg} / 100 \mathrm{~g}$, at 24 and $48 \mathrm{~h}$ in red fruits, respectively. A significant effect of exogenous ethephon was observed on pink and red fruits compared to their respective controls (Figure 4C).
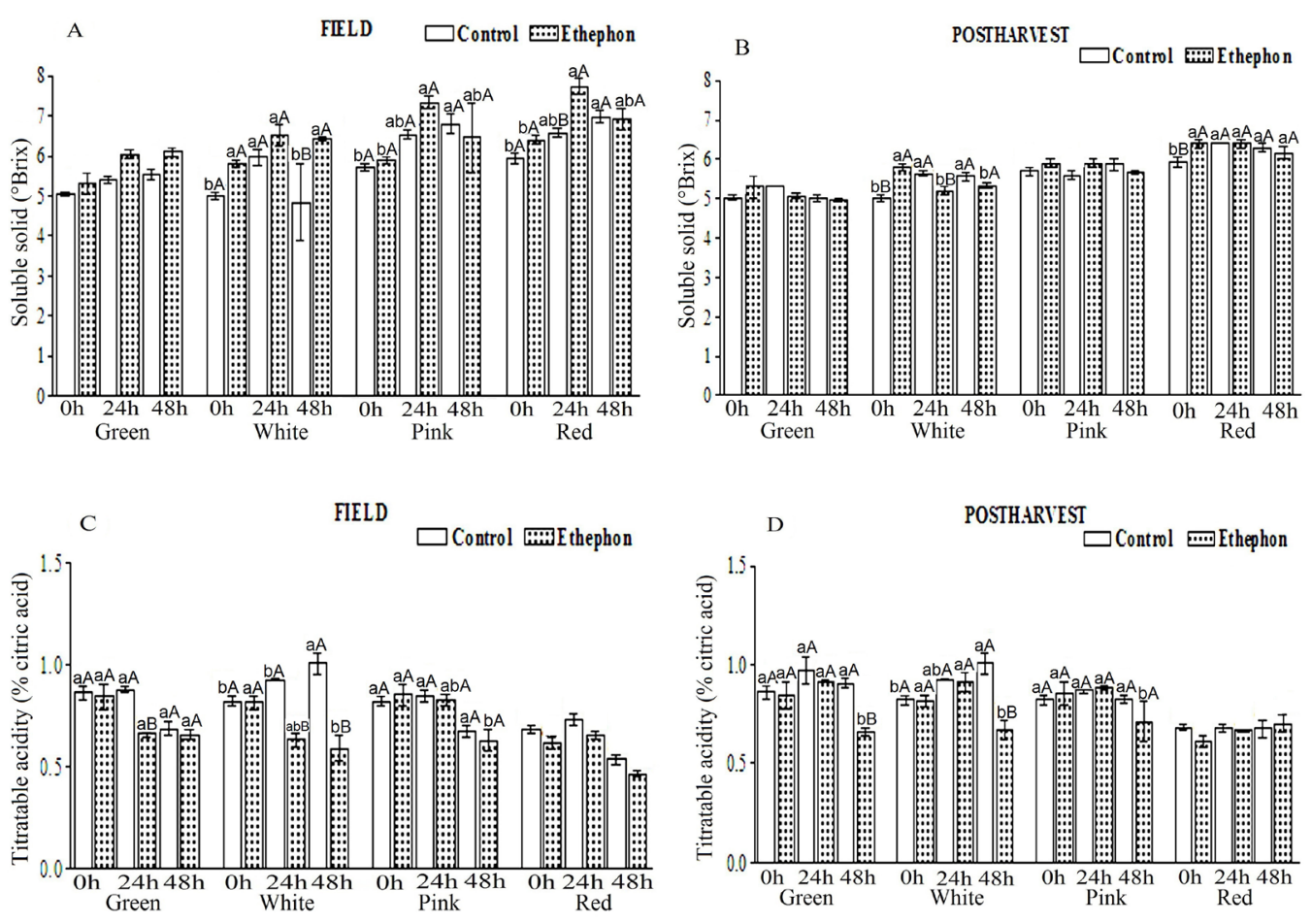

Figure 3. Changes of fruit soluble solid (A, B) and titratable acidity (C, D) in the green, white, pink and red control (open bars) and ethephon-treated (dotted bars) field and postharvest fruits in times 0,24 and $48 \mathrm{~h}$. The error bars represent a standard deviation of three technical repetitions. Means followed by the same lowercase letters between the time intervals of evaluation within each stage in fruits with and without treatment and averages followed by the same uppercase letters between stages in fruits with and without treatment within each time interval did not differ significantly by the Tukey test at $P \leq 0.05$.

Ethylene was found to have a significant effect on the phenolic compound content. Accumulation was observed after $48 \mathrm{~h}$ in green ethephon-treated fruits $(550.01 \pm 6.20 \mathrm{mg} / 100$ g) and during the white stage ( $371.32 \pm 12.62 \mathrm{mg} / 100 \mathrm{~g})$, compared to their controls (145.80 $\pm 6.40 \mathrm{mg} / 100 \mathrm{~g}$ in green fruit and $73.71 \pm 1.34 \mathrm{mg} / 100 \mathrm{~g}$ in white fruit) (Figure 5A). The level of phenolic compounds reduced as the fruit maturated; however, it increased from 24 to $48 \mathrm{~h}$ in all stages. The vitamin $C$ content increased significantly during fruit ripening (Figure 5C). However, the highest concentration was observed at $0 \mathrm{~h}$ after treatment in pink and red fruits $(87.81 \pm 5.16 \mathrm{mg} / 100 \mathrm{~g})$ in comparison to that observed in controls $(69.96 \pm 2.82 \mathrm{mg} / 100 \mathrm{~g})$ (Figure 5C). 

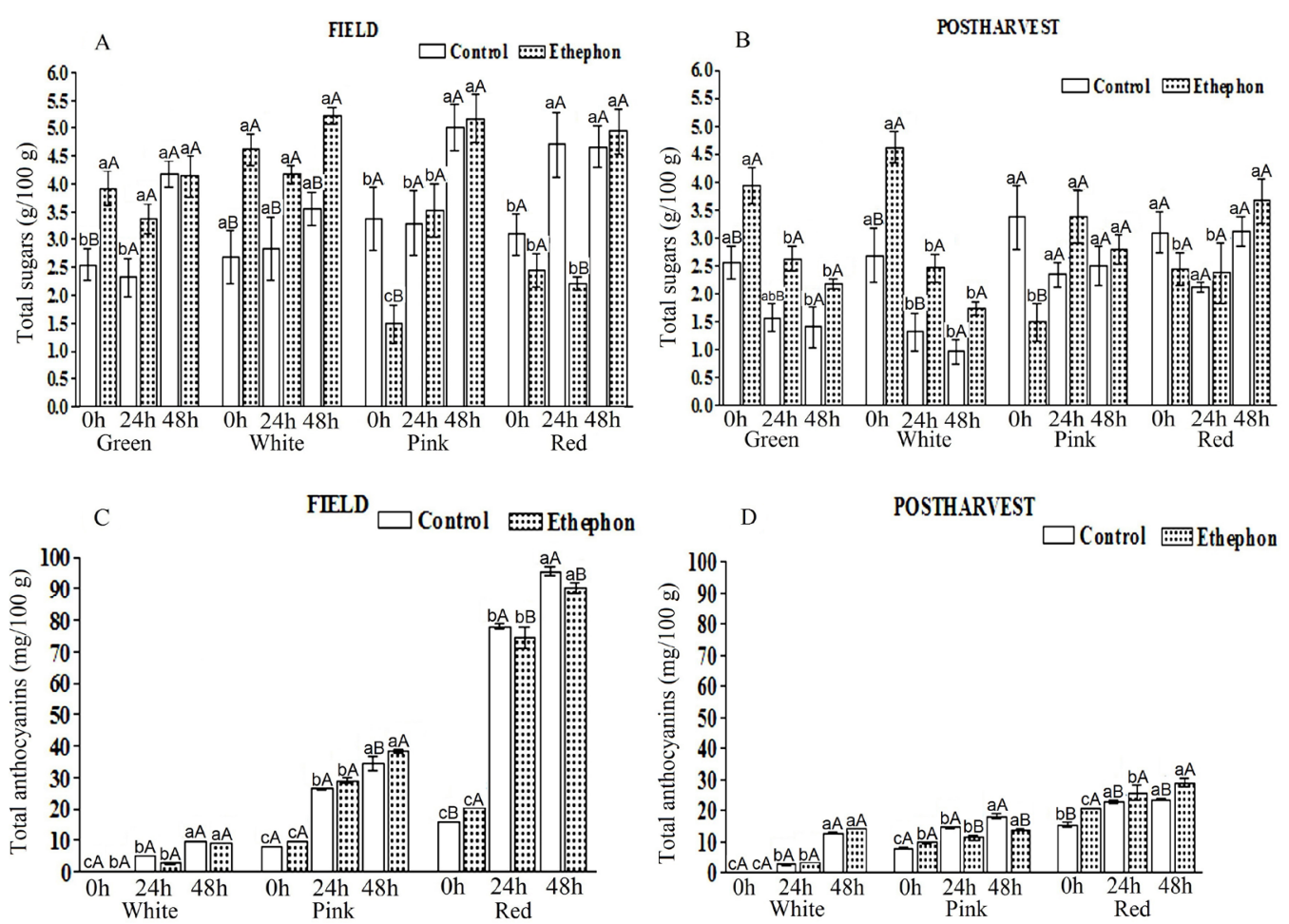

Figure 4. Changes of fruit total sugars (A, B) and total anthocyanins (C, D) content in different stages of development control (open bars) and ethephon-treated (dotted bars) field and postharvest fruits in times 0,24 and $48 \mathrm{~h}$. The error bars represent a standard deviation of three technical repetitions. Means followed by the same lowercase letters between the time intervals of evaluation within each stage in fruits with and without treatment and averages followed by the same uppercase letters between stages in fruits with and without treatment within each time interval did not differ significantly by the Tukey test at $\mathrm{P} \leq 0.05$.

\section{Postharvest assay}

Ethephon treatment did not affect fruit color (data not shown). In general, regardless of the treatment, the loss of firmness was accelerated by growth and maturation, and was $57.13 \pm 4.12$ $\mathrm{N}$ in green fruit and $7.76 \pm 0.22 \mathrm{~N}$ in red fruit at $0 \mathrm{~h}$ (Figure 2B). However, green ethephon-treated fruit had a higher firmness value after $48 \mathrm{~h}(56.04 \pm 1.03 \mathrm{~N})$, compared to the control $(40.53 \pm$ $1.94 \mathrm{~N}$ ) (Figure 2B). Overall, regardless of the treatment, there was an increase in the level of SS between maturity stages. Ethephon led to a significant increase of $5.80 \pm 0.10^{\circ}$ Brix in SS levels in white fruit compared to that observed in the control $\left(5.0 \pm 0.10^{\circ} \mathrm{Brix}\right)$, as well as in red fruit (6.4 $\pm 0.10^{\circ}$ Brix) compared to the control $\left(5.93 \pm 0.11^{\circ} \mathrm{Brix}\right)$ at $0 \mathrm{~h}$ (Figure $3 \mathrm{~B}$ ). The same value was obtained when fruits were treated with ethephon in the pink stage postharvest (Figure 3B). The level of SS increased in field-treated fruits dependent on the maturation stage. An average of $7^{\circ}$ Brix was found for treated red fruits, compared to that obtained in postharvest treated fruits (average value of $6.3^{\circ} \mathrm{Brix}$ ). This was probably due to their attachment to the plant (Figure $3 \mathrm{~A}$ ). Acidity levels decreased during maturation and significant differences were observed within $48 \mathrm{~h}$ in fruit treated with ethephon during the first three stages of development (Figure 3D). The acidity of fruits remained constant both in field and postharvest assays (Figure $3 \mathrm{C}$ and $\mathrm{D}$ ). 

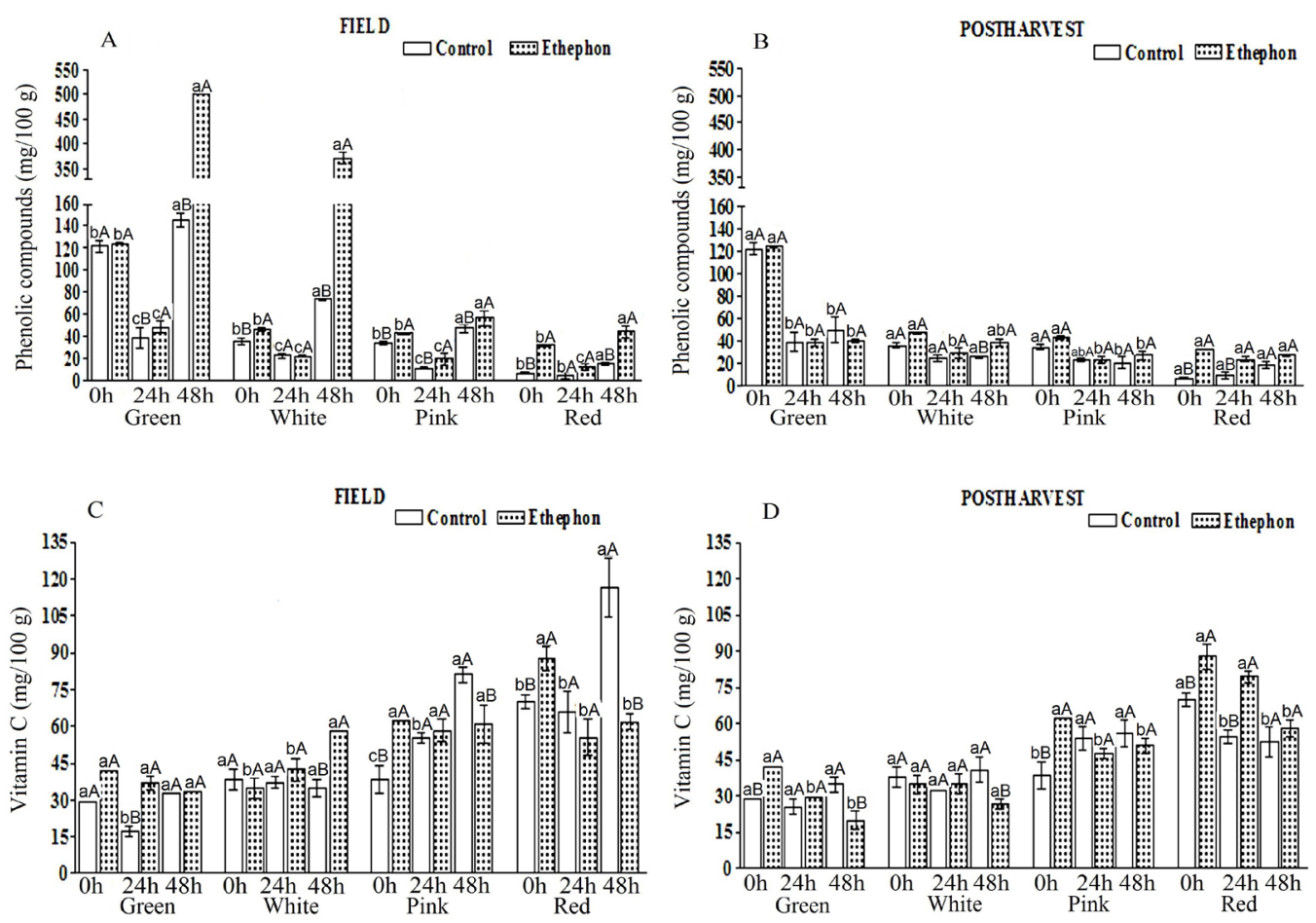

Figure 5. Changes of phenolic compounds (A, B) and vitamin C (C, D) content in different stages of development of control (open bars) and ethephon-treated (dotted bars) field and postharvest fruits in times 0,24 and $48 \mathrm{~h}$. The error bars represent a standard deviation of three technical repetitions. Means followed by the same lowercase letters between the time intervals of evaluation within each stage in fruits with and without treatment and averages followed by the same uppercase letters between stages in fruits with and without treatment within each time interval did not differ significantly by the Tukey test at $P \leq 0.05$.

When analyzing the total sugar content, fruit treated with ethephon at $0 \mathrm{~h}$ accumulated more total sugars in the early stages $(3.92 \pm 0.32 \mathrm{~g} / 100 \mathrm{~g}$ in green fruit and $4.62 \pm 0.28 \mathrm{~g} / 100 \mathrm{~g}$ in white fruit) compared to their respective controls $(2.55 \pm 0.29 \mathrm{~g} / 100 \mathrm{~g}$ in green fruit and $2.69 \pm 0.48$ $\mathrm{g} / 100 \mathrm{~g}$ in white fruit) (Figure 4B). Reduced sugar levels were observed during the pink and red stages and were dependent on the time of application (Figure 4B). Higher total sugar content was observed under field compared to postharvest conditions (Figure 4A and B). The total anthocyanin content increased during fruit ripening and was dependent on the time of application. Red fruits treated with ethephon accumulated more anthocyanins at different evaluation periods than did their controls (Figure 4D). However, a higher average anthocyanin level, which increased 2.45-fold, was observed when red fruits were treated in the field when compared to postharvest tests (Figure 4C and $\mathrm{D}$ ). The phenolic compound content gradually decreased until the end of maturation (Figure 5B) and, with the exception of red fruits, was independent of ethephon treatment. The highest level of phenolic compounds was found in green fruits at $0 \mathrm{~h}$ and was $122.88 \mathrm{mg} / 100 \mathrm{~g}$ (Figure 5B).

A significant increase in vitamin $\mathrm{C}$ content was observed as fruit maturated, showing a significant difference at $0 \mathrm{~h}(62.39 \mathrm{mg} / 100 \mathrm{~g})$ in pink treated fruit, compared to that observed in 
the control $(38.65 \pm 5.53 \mathrm{mg} / 100 \mathrm{~g})$, and in the red treated fruit at $0 \mathrm{~h}(87.81 \pm 5.16 \mathrm{mg} / 100 \mathrm{~g})$ compared that observed in the control $(69.96 \pm 2.82 \mathrm{mg} / 100 \mathrm{~g})$ (Figure 5D). In general, the results of the two tests that measured vitamin $C$ content in fruits followed a similar pattern (Figure $5 \mathrm{C}$ and $D$ ), and showed that ethephon seems to have little influence on the induction of vitamin $C$ synthesis.

\section{DISCUSSION}

Fruit ripening is a complex event that involves the complementary action of hormones in the metabolic changes that occur during maturation. Little is known about ripening and the associated signaling pathways in non-climacteric fruits (Giovannoni, 2004, Merchante et al., 2013). Although strawberry is a non-climacteric fruit, ethylene is produced in limited amounts during ripening and could affect gene expression and maturation (Trainotti et al., 2005; Villarreal et al., 2010; Merchante et al., 2013).

Tranotti et al (2005) evaluated the effect of exogenous ethylene on strawberry development and ripening and found a good correlation between the expression of genes involved in the ethylene signaling pathway, leading to speculation about the pathways activated by ethylene. Bombarelli et al. (2010) previously reported the expression profile of genes involved in auxin, ethylene, and brassinosteroid signaling pathways during fruit ripening. Previously, we used qRT-PCR to analyze the expression profiles of FaETR1 and FaERS1 in response to exogenous ethylene during three developmental stages in the Fragaria x ananassa Duch. cultivar Camino Real (Ayub et al., in press). The pattern of FaETR1 and FaERS1 receptor expression showed the same profile in both field and postharvest tests as that described for cultivar Chandler, in which an increase was observed during the white stage, which was or was not elicited by ethylene (Ayub et al., in press, Trainotti et al, 2005). According to Tian et al. (2000), non-climacteric fruit can have different ethylene receptors and/or receivers, which may have different regulatory functions.

The FaERF2 and FaACO1 transcription factors, which encode components of the ethylene biosynthetic pathway, were highly expressed in the white stage under both conditions. This suggests that exogenous ethylene may not control the expression of these genes during this stage as all receptors/transcription factor/genes under investigation were highly expressed. The FaACO1 gene transcript was expressed in fruit of different stages in both assays; however, the highest level of expression was observed in the postharvest assay. Trainotti et al. (2005) observed increased expression of FaACO1 in white and red fruit within $24 \mathrm{~h}$, which is consistent with the results of the present postharvest study, in which the highest accumulation of transcript was observed within $4 \mathrm{~h}$. Merchante et al. (2013) also showed that there was higher expression of FaACO1 gene receptacles in the white and red stages.

In this study, the pattern of gene expression during strawberry ripening was stage dependent, whereby the largest change in gene expressed occurred in white fruits during the growing stage. This result reflects changes in gene expression throughout the entire strawberry fruit (achenes plus receptacle), which can be difficult to interpret because of the sample heterogeneity. Taken together, the results have shown that in the Fragaria ananassa cultivar. Camino real, exogenous ethylene has no effect on the expression of genes involved in ethylene signaling, whereas endogenous ethylene promotes whole fruit ripening. In general, exogenous ethephon treatment influenced the levels of total sugars, anthocyanins, phenolic compounds, and vitamin $C$ in strawberries at different stages of maturation during field sampling. These results were compared to the postharvest analyses, when fruit development continued under conditions 
that were favorable to it, even after harvest. However, fruits accumulated the highest level of total sugars during vine development, compared to that accumulated postharvest. This is mainly because strawberries accumulate sugar that is imported from the leaves during ripening (Villarreal et al., 2010). The starch reserves of the fruit make an important contribution to the sugar content of some fruit (Souleyre et al., 2004). Those authors observed starch accumulation in the early stages of strawberry maturation, which was rapidly degraded during fruit ripening. In our analysis, fully grown and developed fruits accumulated more sugars in response to ethephon in both trials. One possible source of simple sugars is from the degradation of cell wall components (Villarreal et al., 2010). If these sugars came from cell-wall polymers, this may indicate that ethylene influences changes in cell-wall hydrolases during the postharvest period (Villarreal et al., 2010), which may also occur in treated fruits attached to the plant.

Strawberries are a source of phenolic compounds such as flavonoids, phenolic acid derivatives, and anthocyanins, which are all synthesized by the phenylpropanoid pathway (Muñoz et al., 2011), in which phenylalanine ammonialyase (PAL) is the key enzyme (Singh et al., 2010). A slight increase in the anthocyanin content in postharvest red fruits treated with ethephon was observed. Villarreal et al. (2010) observed an increase in anthocyanin in strawberries treated with ethephon during the white stage, which suggests that ethylene can stimulate anthocyanin accumulation and chlorophyll degradation in strawberries. In addition, increased PAL activity was observed in fruit treated with ethephon (Villarreal et al., 2010). Fruits at different ripening stages may have different thresholds to ethylene sensitivity (Tian et al., 2000). In grapes, El-Kereamy et al. (2003) observed that anthocyanin levels were higher in ethylene-treated berries, suggesting that ethylene accelerates anthocyanin synthesis and berry color.

The amount and composition of phenolic compounds changes during strawberry ripening (Martínez et al., 2001). In the present study, we observed two peaks of accumulation in green and white fruits treated with ethephon during the $48 \mathrm{~h}$ test in the field, which decreased constantly during ripening. Phenolic compounds produced by the phenylpropanoid pathway play an important role in the growth and development of plants as well as in their interaction with the environment (Singh et al., 2010). Jiang et al. (2001) reported a direct correlation between PAL activity and phenolic compounds, since treatment of the strawberry cultivar Everest with an ethylene inhibitor (MCP-1) led to delayed anthocyanin and phenolic compound production. However, Villarreal et al. (2010) observed a significant increase in PAL activity and a decrease in the phenolic content during the ripening of white strawberries treated with ethephon, indicating that a direct correlation is lacking. However, molecular analyzes of the strawberry cultivar Camarosa during ripening led Muñoz et al. (2011) to observe higher PAL expression levels in green and red fruit compared to white. These data suggest that differences in the level of anthocyanins and phenolic compounds across stages in the present study may be related to PAL activity.

Vitamin C content increased over time during growth and development of fruit (Lee and Kader, 2000), and significant differences were observed following ethephon application at the later stages of fruit ripening. Postharvest treatment with ethrel can stimulate changes in ascorbic acid content, which influences total carbohydrate metabolism (Mehta et al., 1980). The level of vitamin $\mathrm{C}$ in fruits and vegetables can be influenced by several factors, such as climatic conditions, cultural practices, maturity, harvesting methods, and post-harvest handling (Lee and Kader, 2000).

The results of the present study show that ethylene can stimulate the expression of receptors (FaETR1 and FaERS1), transcription factors (FaERF2), and ethylene biosynthesis genes (FaACO1), and affect the phytochemical responses of this hormone during the regulation 
of biosynthetic pathways of sugars, anthocyanins, phenols, and vitamin C in strawberry. Taken together, these data show that ethylene can trigger these same physiological and biochemical responses during ripening of non-climacteric fruit.

\title{
Conflicts of interest
}

The authors declare no conflict of interest.

\section{ACKNOWLEDGMENTS}

\author{
Research supported by CAPES, Fundação Araucária, CNPq, and UEPG.
}

\section{REFERENCES}

AOAC (2002). Official methods of analysis of the association of official analytical chemistry. 17th edn. AOAC International, Gaithersburg.

Ayub RA, Lopes PZ, Almeida AT, et al. (2015). Effect of exogenous ethylene on the expression of FaETR1 and FaERS1 genes during ripening of strawberry cv. Camino Real. Acta Horticult. (in press).

Bombarely A, Merchante C, Csukasi F, Cruz-Rus E, et al. (2010). Generation and analysis of ESTs from strawberry (Fragaria $x$ ananassa) fruits and evaluation of their utility in genetic and molecular studies. BMC Genomics 11: 503.

Chai YM, Jia HF, Li CL, Dong QH, et al. (2011). FaPYR1 is involved in strawberry fruit ripening. J. Exp. Bot. 62: 5079-5089.

Cumplido-Laso G, Medina-Puche L, Moyano E, Hoffmann T, et al. (2012). The fruit ripening-related gene FaAAT2 encodes an acyl transferase involved in strawberry aroma biogenesis. J. Exp. Bot. 63: 4275-4290.

Dubois M, Gilles KA, Hamilton JK, Rebers PA, et al. (1956). Colorimetric method for determination of sugars and related substances. Anal. Chem. 28: 350-356.

El-Kereamy A, Chervin C, Roustan JP, Cheynier V, et al. (2003). Exogenous ethylene stimulates the long-term expression of genes related to anthocyanin biosynthesis in grape berries. Physiol. Plantarum 119: 175-182.

Giovannoni JJ (2004). Genetic regulation of fruit development and ripening. Plant Cell 16 (Suppl): S170-S180.

Giusti M and Wrolstad RE (2003). Acylatedanthocyanins from edible sources and their applications in food systems. Biochem. Eng. J. 14: 217-225.

Ji K, Chen P, Sun L, Wang Y, et al. (2012). Non-climacteric ripening in strawberry fruit is linked to ABA, FaNCED2 and FaCYP707A1. Funct. Plant Biol. 39: 351-357.

Jiang Y, Joyce DC and Terry LA (2001). 1-Methylcyclopropene treatment affects strawberry fruit Decay. Postharvest Biol. Technol. 23: 227-232.

Lee SK and Kader AA (2000). Preharvest and postharvest factors influencing vitamin C content of horticultural crops. Postharvest Biol. Technol. 20: 207-220.

Martínez GA, Civello PM, Chaves AR and Añón MC (2001).Characterization of peroxidase-mediated chlorophyll bleaching in strawberry fruit. Phytochemistry 58: 379-387.

McGuire RG (1992). Reporting of objective color measurements. HortScience 27: 1254-1255.

Mehta PM, Suma TK and Prasad TK (1980). Effect of ethrel treatment on the postharvest changes in the turnover of ascorbic acid and reducing sugar in Achrassapota fruits. J. Biosci. 2: 305-310.

Merchante C, Vallarino JZ, Osorio S, Aragüez I, et al. (2013). Ethylene is involved in strawberry fruit ripening in an organspecific manner. J. Exp. Bot. 64: 4421-4439.

Muñoz C, Sánchez-Sevilla JF, Botella MA, Hoffmann T, et al. (2011). Polyphenol composition in the ripe fruits of Fragaria species and transcriptional analyses of key genes in the pathway. J. Agric. Food Chem. 59: 12598-12604.

Quesada MA, Blanco-Portales R, Posé S, García-Gago JA, et al. (2009). Antisense down-regulation of the FAPG1 gene reveals an unexpected central role for polygalacturonase in strawberry fruit softening. Plant Physiol. 150: 1022-1032.

Shakeel SN, Wang X, Binder BM and Schaller GE (2013). Mechanisms of signal transduction by ethylene: overlapping and non-overlapping signalling roles in a receptor family. AoB Plants 5: 1-16.

Shulaev V, Sargent DJ, Crowhurst RN, Mockler, TC, et al. (2011). The genome of woodland strawberry (Fragaria vesca). Nat. Genet. 43: 109-118.

Singh R, Rastogi S and Dwivedi UN (2010). Phenylpropanoid metabolism in ripening fruits. Compr. Rev. Food Sci. Fruits 9 : 
398-416.

Singleton VL and Rossi JA (1965). Colorimetry of total phenolics with phosphomolybdic-phosphotungstic acid reagents. Am. J. Enol. Viticult. 16: 144-158.

Souleyre EJF, lannetta PPM, Ross HA, Hancock RD, et al. (2004). Starch metabolism in developing strawberry (Fragaria $x$ ananassa) fruits. Physiol. Plantarum 121: 369-376.

Sun JH, Luo JJ, Tian L, Li CL, et al. (2013). New evidence for the role of ethylene in strawberry fruit ripening. J. Plant Growth Regul. 32: 461-470.

Symons GM, Ghua YJ, Ross JJ, Quittenden LJ, et al. (2012). Hormonal changes during non-climateric ripening in strawberry. J. Exp. Bot. 12: 2-10.

Tian MS, Prakash S, Elgar HJ and Young H (2000). Responses of strawberry fruit to 1-Methylcyclopropene (1-MCP) and ethylene. Plant Growth Regul. 32: 83-90.

Trainotti L, Pavanello A and Casadoro G (2005). Different ethylene receptors show an increased expression during the ripening of strawberries: does such an increment imply a role for ethylene in the ripening of these non-climacteric fruits? J. Exp. Bot. 56: 2037-2046.

Villarreal NM, Bustamante CA, Civello PM and Martinez GA (2010). Effect of ethylene and 1-MCP treatments on strawberry fruit ripening. J. Sci. Food Agr. 90: 683-689.

Zhao Q and Guo HW (2011). Paradigms and paradox in the ethylene signaling pathway and interaction network. Mol. Plant 4: 626-634. 